\title{
FUNCTIONAL CHARACTERISTICS OF SPECIALIZED CIRCUIT TRAINING FOR KARATE COMPETITORS
}

\author{
Albena Alexandrova, Radoslav Penov, Lubomir Petrov, Dilyana Zaykova \\ National Sports Academy "Vassil Levski"
}

\begin{abstract}
Successful performance in the Kumite discipline of Karate-do requires well developed aerobic and anaerobic cell-systems for supplying energy. Therefore, more and more often over the recent years, the preparation of martial arts athletes has included intensive interval training sessions following the Tabata method. The objective of this survey was to create a highly-intensive Tabata-based circuit training that is suitable for the functional preparation of Karate competitors and for defining the physiological and the biochemical characteristics of the training load through measuring the heart rate and the concentration of lactate in the peripheral blood. A group of six Karate practitioners, all Kumite competitors, took part in the survey. They performed tree times 10 exercises with Karate-technique elements following the classical Tabata scheme of 20 seconds work with a maximum number of repetitions and 10 seconds of break. The results proved that; 1) The heart rate increased after each circuit and exceeded $180 \mathrm{bpm}$, and in the break time it went down to 120-140 bpm; 2) The lactate concentration in the blood rose progressively after the first two circuits, and after finishing the last circle an overall decrease was registered regarding this indicator $(9.3 \pm 3.32 \mathrm{vs} 13.4 \pm 2.39 \mathrm{vs} 11.8 \pm 1.63 \mathrm{mmol} / \mathrm{L}$, respectively). In conclusion, the intensity of the latter circuit training model is very high because the levels of blood lactate after performing each circuit of the training were higher than the respective concentrations after Kumite competition matches at the same heart rates.
\end{abstract}

Key words: Karate, kumite, lactate, heart rate, Tabata-based circuit training

\section{INTRODUCTION}

In addition to optimized tactical and technical preparation, the discipline of Kumite in Karate requires a variety of motoric qualities developed by the respective physiological and bio-chemical mechanisms (Chaabèneet al., 2012; Chaabèneet al., 2014). This requires the application of complex training aimed at loading the various muscle groups, the development of a variety of physical qualities, and the activation of energy-provision systems both at aerobic and anaerobic conditions.

The previously existing hypothesis (Lehmann and Jedliczka, 1998; Schmidt and Perry, 1976) assumed that the anaerobic metabolism dominated during Kumite. On the basis of recording the ratio of active work vs. passive motion, however, it is currently believed that during Kumite the main energy provider is the aerobic system with a share of $77.8 \pm 5.8 \%$ of the overall energy supply (Beneke et al., 2004). The need for both aerobic and anaerobic support of motions during Karate competitions demands that elite Karate competitors take a mixed training routine in order to adapt to different metabolic paths. Therefore, highintensity interval training (HIT) is used in various combat sports because of the fact that it develops both aerobic and anaerobic energy mechanisms (Franchiniet al., 2016).

Tabata training is currently used as a synonym of HIT. It consists of eight 20 -second work sessions comprising aerobic exercises with super-maximum intensity $(170 \%$ of $\left.\mathrm{VO}_{2} \max \right)$ or power exercises with maximum number of repetitions and a 10 -second break 
between the sessions. The total duration is 4 minutes and it is marked as a segment (Tabata et al., 1996) (or circuit). This performance can be repeated four times with breaks of one minute, which forms a 20-minute session (Embertset al., 2013). During the pilot study of six weeks, doing Tabata training five times a week brought about the increase of $\mathrm{VO}_{2}$ max with 7 $\mathrm{mL} / \mathrm{kg} / \mathrm{min}$, and the anaerobic capacity grew by $28 \%$ (Tabata et al., 1996). These results encourage the development of various HIT programs that include exercises performed in the classical model of 20-10 (20 seconds of workout and 10 seconds of rest).

Thus, the purpose of the here-by survey was to design a highly intensive circuit pro- gram following the Tabata method that is suitable for the functional preparation of Karate competitors and for determining the physiological and biochemical characteristics of the training load by measuring the heart rate and the concentration of lactate in peripheral blood.

\section{METHODS}

\section{Participants}

The study involved a group of six Karate practitioners, all competitors in Kumite, aged 20 to 25 , with 6 to 20 years of experience in Karate ( $10.8 \pm 5.56$ years). The anthropometric data of the subjects is listed in table 1 .

Table 1. Anthropometric data of the karate practitioners studied

\begin{tabular}{ccccc}
\hline No & Age (years) & Height $\mathbf{~ c m}$ & Weight kg & BMI kg.m $^{-2}$ \\
\hline S1 & 20 & 183 & 80 & 23.9 \\
S2 & 25 & 175 & 64 & 20.9 \\
S3 & 22 & 178 & 68 & 21.5 \\
S4 & 22 & 175 & 72 & 23.5 \\
S5 & 22 & 183 & 76 & 22.7 \\
S6 & 25 & 183 & 77 & 23.0 \\
\hline Average value & $\mathbf{2 2 . 7}$ & $\mathbf{1 7 9 . 5}$ & $\mathbf{7 2 . 8}$ & $\mathbf{2 2 . 6}$ \\
\hline SD & $\mathbf{1 . 9 7}$ & $\mathbf{3 . 9 9}$ & $\mathbf{6 . 0 1}$ & $\mathbf{1 . 1 7}$ \\
SE & 0.80 & 1.63 & 2.46 & 0.48 \\
Min. & 20 & 175 & 64 & 20.9 \\
Max. & 25 & 183 & 80 & 23.9 \\
\hline
\end{tabular}

Three of the participants were nationalteam competitors, one participant was at national level, and the remaining two had ceased active competitions but trained regularly. The subjects were informed of the purpose, the objectives, and the organization of the survey and signed Informed Agreements.

\section{Study design}

A circuit training model was created comprising 10 exercises performed by the classical Tabata scheme: 20 seconds of workout with maximum number of repetitions and $10 \mathrm{sec}-$ onds of rest, or a total of 290 seconds. These were performed in sequence in three rounds with 5 minutes of rest in between them. Almost all exercises contained elements of Karate techniques. The lactate concentration in peripheral blood was studied (blood was drawn from the ear lobe) immediately after the warm-up and after each round. The heart rate was measured at rest and after the first, the second and the third rounds of the circuit training.

\section{Warm-up description}

The warm-up continued for 15 minutes and included 8 minutes of running exercises and 7 minutes of exercises for all joints. 


\section{Description and characteristics of the exercises included in each session of the circuit training}

Exercise 1. Routine: aiming to develop the explosive strength of the legs. It is performed from a standing position on a 50-centimeter platform. The exercise begins with a jump towards the floor and continues with four jumps above three cones in the following sequence: a jump forward with knees on from of the chest, a jump to the left, a jump to the right, and a jump forward. The exercise ends with two punches (Gyaku Tsuki) onto a bunch bag. It is obligatory that jumps be performed by touching the ground only once.

Exercise 2. Push-ups onto a heavy ball for developing the explosive power of the arms. The exercise was performed from push up position, as one hand was onto the heavy ball. Arms bent in the elbow joint, and then extended as the hand that is onto the heavy ball switched. The exercise was performed by detaching from the contact surface and was of explosive-dynamic character.

Exercise 3. Half squat and pushing a bar above the head for developing the power stamina of the legs. From a standing position with a 20-kilogram bar at chest level a half-squat is performed and the bar is pushed above the head.
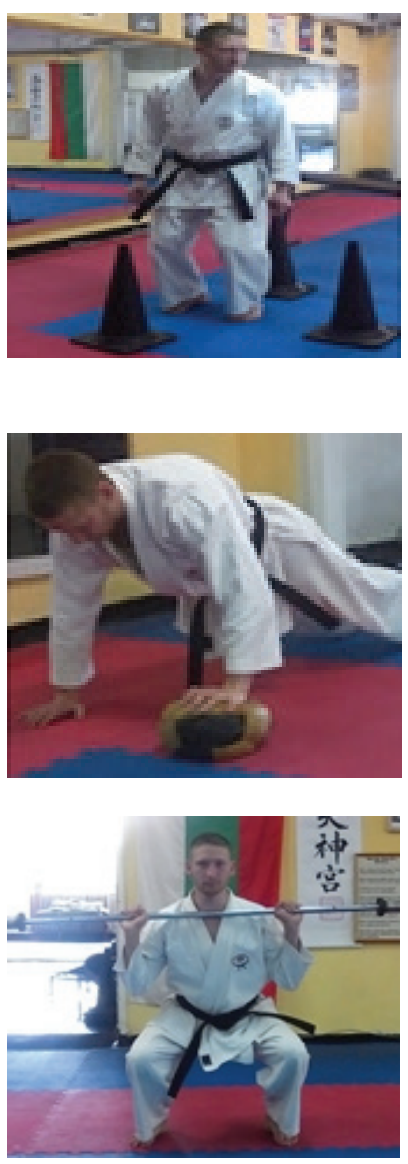

Exercise 4. Punches with the arms (Kizami - Gyaku Tsuki) against the resistance of an elastic band. This exercise aims to develop the power stamina of the arms and improves the technical preparation. From combat position (Kumite Dachi) punches are performed (Kizami - Gyaku Tsuki) as the elastic band is held in both hands with a 1-meter shift in position (Yori Ashi).

Exercise 5. Roller: aimed to develop the power stamina of the abdominal muscles. The initial position was with knees on the mat and arms were stretched in the elbows, holding a roller (a device for training the abdominal muscles). At the middle phase of the exercise the stomach needed to touch the floor, which was followed by a return to the initial position.

Exercise 6. Running sideways with a change of direction: aiming to develop the speed stamina of the legs. From standing position, running sideways was performed to a cone on the right, a half squat followed as the cone was touched with the right hand. Then a change in direction followed and the same sequence was performed to a cone on the left. The distance between the cones was 3 meters. When moving sideways legs were not allowed to cross or come close to each
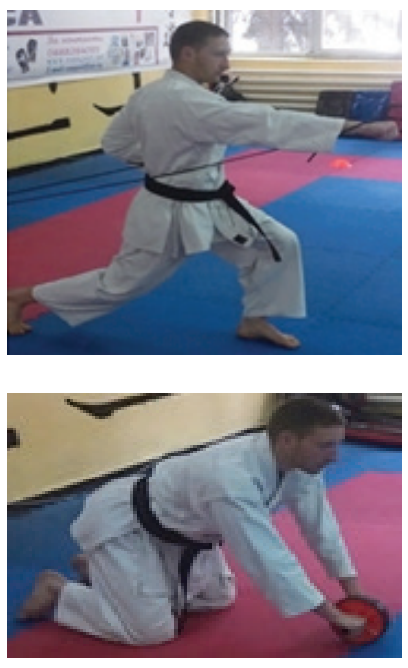
other.

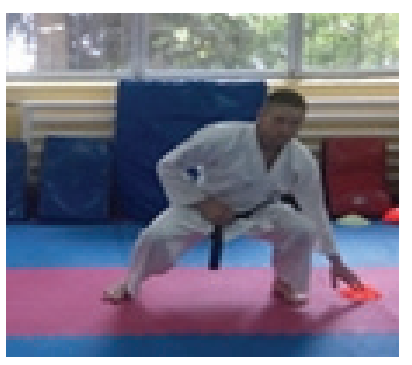


Exercise 7. A forward thrust with a bar: aiming to develop the speed stamina of arms. An 8-kilogram bar was held in standing position with flexed arms at chest level. As the arms extended in the elbow joints, the bar was thrust forward at the level of the chin. In the meantime the feet assumed a fight stance. After that the initial position was assumed. The exercise was repeated as the leading foot changed.

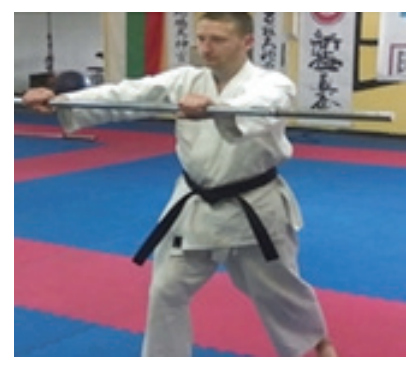

Exercise 8. A simultaneous performance of a forward lunge and an imitation hand punch while holding a grip. This exercise aims to develop the power stamina of both the legs and the arms. The initial position was standing position with hands at the chest level holding grips for strengthening the grip power of the hand. A forward lunge was performed until the knee of the rear leg touched the floor as the axis of the body remained vertical. One hand was in guard position at chin level and the other one performed a Gyaku Tsuki punch (a straight punch with the rear hand) and tightened the grip at the end of the punch. The exercise was performed with consecutive switching the legs.

Exercise 9. Pulling a 16-kilogram dumb-bell: aiming to develop power stamina. From half squat and holding the dumb-bell with two hands on top, the dumb-bell is pulled upwards vertically. At the final stage the dumb-bell was at the level of the chin.
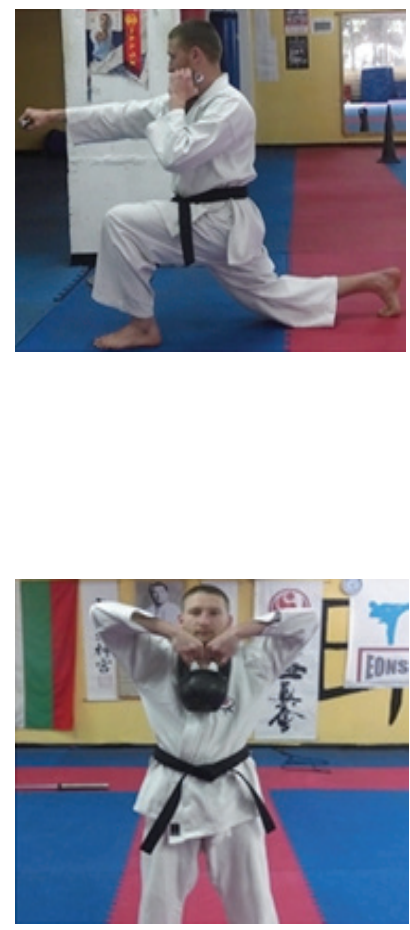

Exercise 10. Kicks with the leg: aiming to develop the speed stamina of the legs. From combat position, a Mawashi Geri kick is performed with the front leg at the height of the belt and is delivered onto a kickbag.

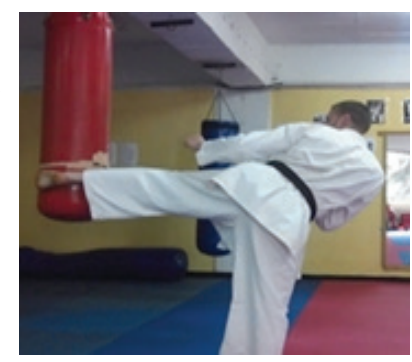

\section{Registration of Heart Rate}

The heart rate (HR) was registered with the use of a pulse-tester (Sigma) and was recorded "beat by beat" by means of a TEMEO telemetric system from the Security Solutions Institute Company, Bulgaria. Acceleration was recorded in the three orthogonal axes (X, Y и Z) per every $20 \mathrm{~ms}$ by means of in-built three-dimensional accelerometer.

Determining the lactate concentration
Lactate concentration (La) was determined by means of an automatic lactate analyzer Lactate Pro 2 LT-1730by the Japanese company Arkray Global Business Inc.

\section{Statistical analysis}

The statistical analysis was conducted by means of the SPSS.19 Packet, (IBM, USA). To determine the statistical credibility, the average values were processed with one-way ANOVA for dependent samples by using Bon- 
ferroni post hoc test. The average values are presented in the text with the standard deviation $( \pm \mathrm{SD}$, and in the graphs they are presented with the standard error $( \pm \mathrm{SE})$.

\section{RESULTS}

Table 2 presents the individual values of the lactate concentration after the warm-up and after the first, second, and third rounds of the circuit training.

Table 2. Individual and average values of the lactate concentration

\begin{tabular}{|c|c|c|c|c|}
\hline No & $\begin{array}{c}\text { La after warm- } \\
\text { up } \\
\end{array}$ & $\begin{array}{c}\text { La after first } \\
\text { round }\end{array}$ & $\begin{array}{c}\text { La after second } \\
\text { round }\end{array}$ & $\begin{array}{c}\text { La after third } \\
\text { round }\end{array}$ \\
\hline & $\mathrm{mmol} / \mathrm{L}$ & $\mathrm{mmol} / \mathrm{L}$ & $\mathrm{mmol} / \mathrm{L}$ & $\mathrm{mmol} / \mathrm{L}$ \\
\hline $\mathrm{S} 1$ & 1.2 & 10.6 & 14.2 & 11.7 \\
\hline S2 & 0.9 & 6.0 & 11.7 & 12.2 \\
\hline S3 & 1.3 & 9.7 & 15.6 & 10.7 \\
\hline $\mathrm{S} 4$ & 1.1 & 8.8 & 11.5 & 14.4 \\
\hline S5 & 1.2 & 14.7 & 16.6 & \\
\hline S6 & 1.0 & 5.7 & 10.9 & 10.2 \\
\hline Average value & 1.1 & 9.3 & $13.4^{*}$ & $11.8^{\star *}$ \\
\hline SD & 0.15 & 3.32 & 2.39 & 1.63 \\
\hline SE & 0.06 & 1.36 & 0.97 & 0.73 \\
\hline Min. & 0.9 & 5.7 & 10.9 & 10.2 \\
\hline Max. & 1.3 & 14.7 & 16.6 & 14.4 \\
\hline
\end{tabular}

* $-\mathrm{p}<0.05$ compared to the concentration of La after the first round

${ }^{*}-p<0.01$ compared to the concentration of La after the first round

The average value of the lactate after the warm-up was $1.1 \mathrm{mmol} / \mathrm{L}$. After the first round of the circuit training, the lactate reached maximum values of $14.7 \mathrm{mmol} / \mathrm{L}$, and the average values for this round were $9.3 \mathrm{mmol} / \mathrm{L}$. After the second round the average levels of lactate concentration rose up to $13.4 \pm 2.39 \mathrm{mmol} / \mathrm{L}$, as the maximum lactate concentration level reached $16.6 \mathrm{mmol} / \mathrm{L}$. After the third round the average levels of lactate concentration were $11.8 \mathrm{mmol} / \mathrm{L}$, and the maximum lactate concentration level reached $14.4 \mathrm{mmol} / \mathrm{L}$. The minimum lactate values were high, too, in all three rounds, and their respective values were the following: $5.7 \mathrm{mmol} / \mathrm{L}, 10.9 \mathrm{mmol} / \mathrm{L}, 10.2$ $\mathrm{mmol} / \mathrm{L}$. A slight reduction of lactate concen- tration after the third round was observed with competitors $\mathrm{S} 1$ и $\mathrm{S} 3$.

The averaged data of the lactate concentration after the warm-up, and after the first second, and the third round indicated a statistically significant increase in the values after the second round in comparison to the first one $(\mathrm{p}<0.05)$, and the same was noticed after the third round in comparison with $(p<0.01)$. No significant increase was observed between the values after the third round in comparison to the second round.

Figure 1 presents the recordings of the heart rate of participants $\mathrm{S} 1$ and $\mathrm{S} 3$, respectively. 
A

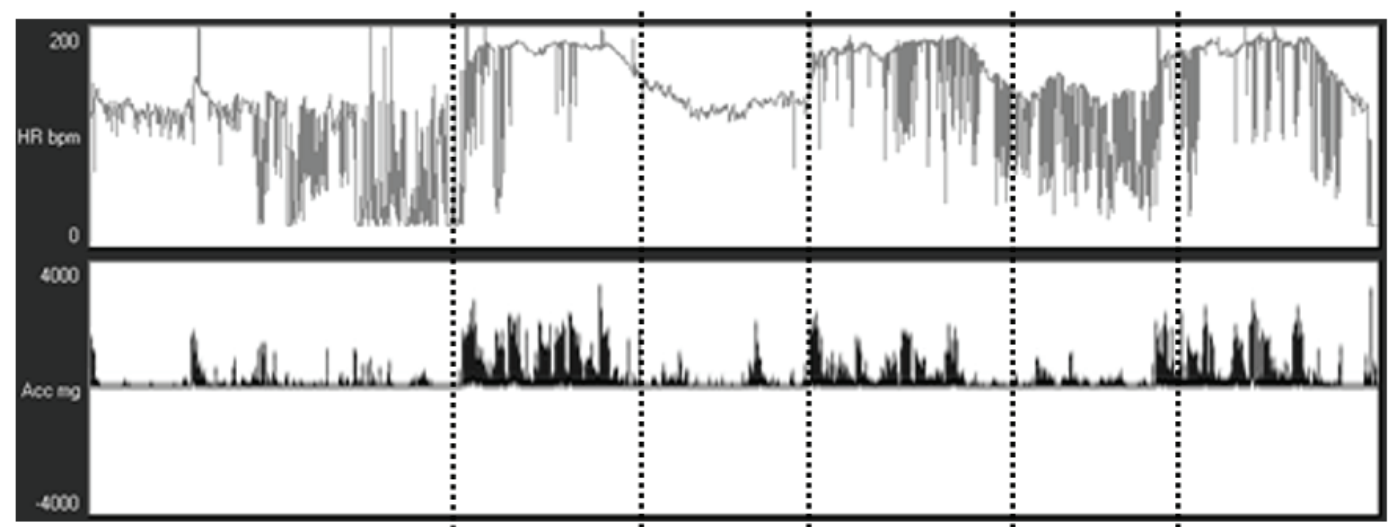

Warm-up $\quad \begin{array}{llllll}\text { Round I } & \text { Rest } & \text { Round II } & \text { Rest } & \text { Round III }\end{array}$

B

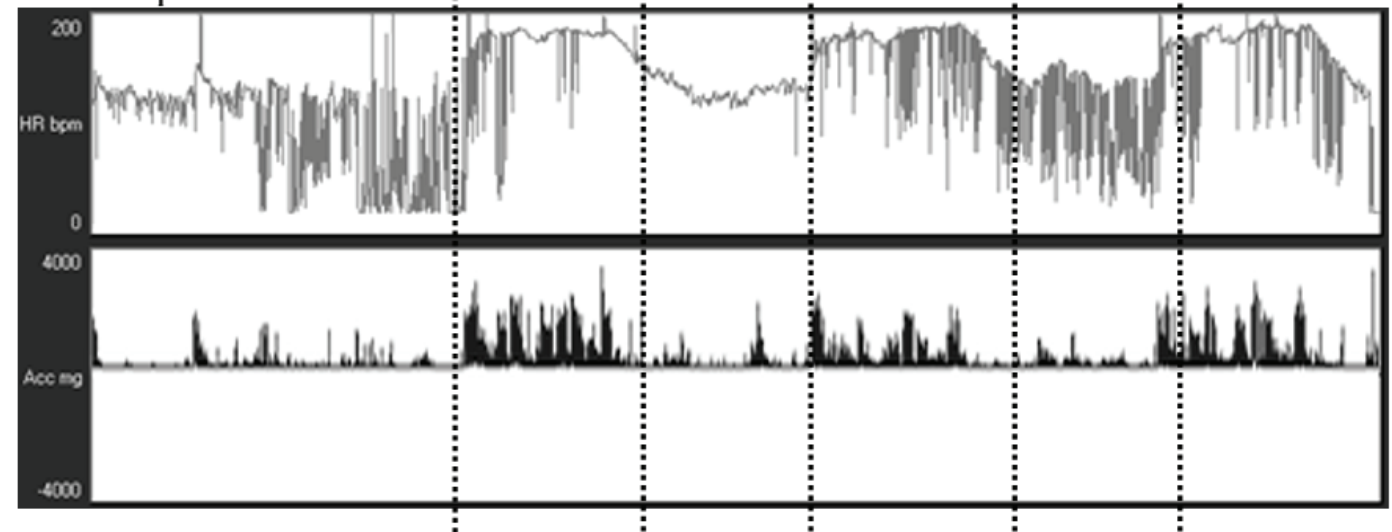

Figure 1. Heart rate recording and physical activity recording (Acc-resultingvector of axes X, $Y u Z$ of the accelerometer) during the warm-up and the three rounds of the circuit training of participants $S 1$ (A) and $S 3(B)$

The individual values of the heart rates of practitioners rose, and the highest levels were all participants are presented in Figure 2. The recorded after the first round with competitors initial values varied from $90 \mathrm{bpm}$ for competi- S1 (195 bpm) and S2 (191 bpm). During the tor S2 to $129 \mathrm{bpm}$ for competitor S3. During breaks, the heart rate dropped and varied from the work circuits the heart rate of all karate 120 to $140 \mathrm{bpm}$.

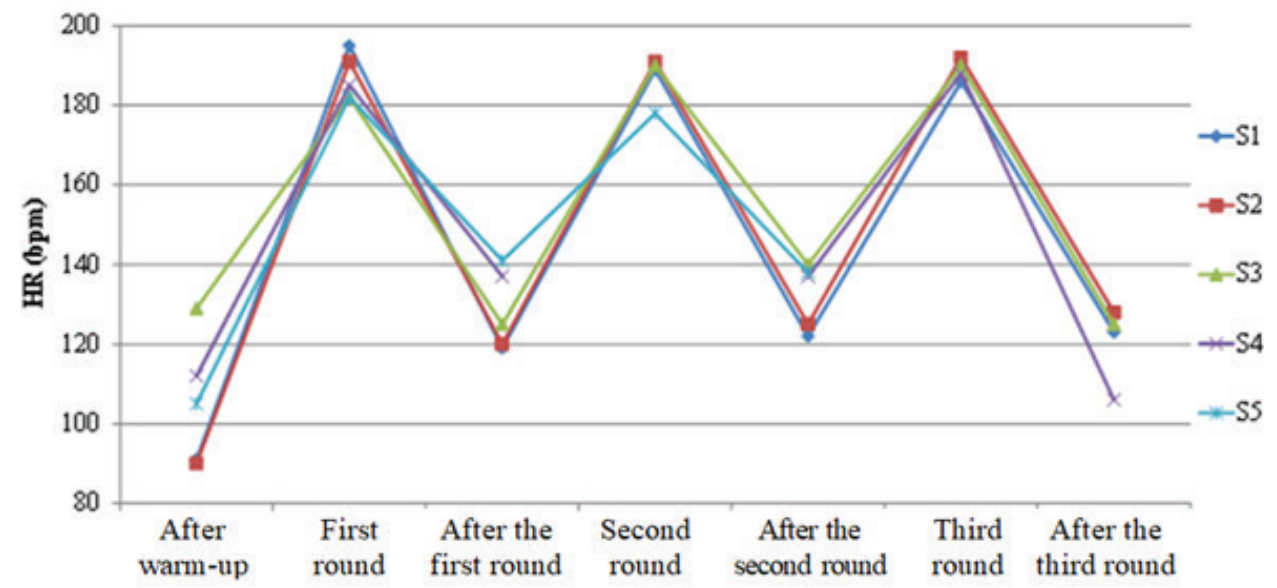

Figure 2. Individual values of the heart rate after the warm-up and after the first, second, and third round of the circuit training for the first five competitors 
The average values indicated a significant increase in the heart rate during the work rounds in comparison with the initial values from $(105.4 \pm 16.6 \mathrm{bpm})$ to $187 \pm 5.79 \mathrm{bpm}$ during work round one, $187 \pm 6.06 \mathrm{bpm}$ during the second round and $189.5 \pm 2.58 \mathrm{bpm}$ during the third round (Figure 3). In the breaks, the heart rate improved slightly and reached similar values, which significantly exceed the initial ones. - $128.4 \pm 10.04 \mathrm{bpm}$ after round one; $132.3 \pm 8.26 \mathrm{bpm}$ after round twoand $120.5 \pm$ $9.88 \mathrm{bpm}$ after round 3 (Figure 3 ).

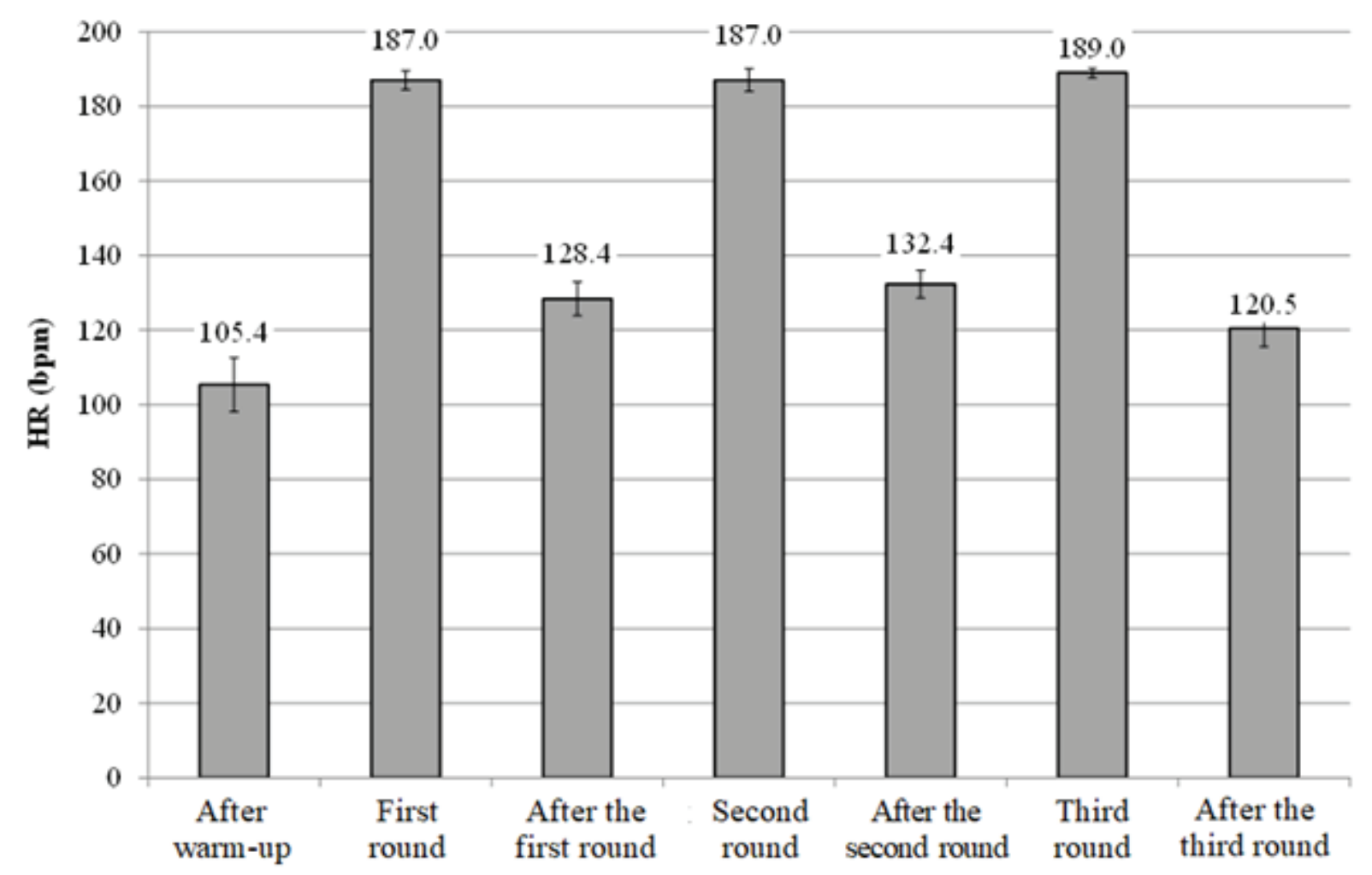

Figure 3. Average values of the heart rate at rest, after the first, second, and the third round of the circuit training for the first five competitors

\section{DISCUSSION}

The purpose of the survey was to construct and try a circuit training version that contains Karate elements and develops qualities and muscle groups that are important for Karate. In order to determine the efficiency of this training we studied the lactate concentration in the blood and the heart rate after the warm-up and after the individual rounds of the training.

As the circuit training progressed, the lactate concentration in the blood rose progressively after the first two rounds. A decrease of this indicator was registered after the last round. In the case of competitor S4, a higher lactate concentration was measured after the end of the raining. The average lactate concentration measured after round two was 13.4 $\mathrm{mmol} / \mathrm{L}$, and after round three it was 11.8 $\mathrm{mmol} / \mathrm{L}$.

During a competition (the National Shotokan Championship) we measured an average value of $6.5 \pm 3.09 \mathrm{mmol} / \mathrm{L}$ after the third match (unpublished data). Other authors (Tabben et al., 2013) report an average lactate concentration of $4.2 \pm 1.2 \mathrm{mmol} / \mathrm{L}$ after official Kumite matches. This shows that the intensity of the circuit training we designed is a lot higher than the competition strain. It 
is shown that at various trainings, the level of lactate varies depending on the qualification of the karate practitioners. Competitors at the national level show higher concentrations of lactate in the blood than international-level competitors after technical, tactical, and conditioning training sessions and free sparring (Tabben et al., 2014). In the same survey the highest lactate concentrations were measured after free sparring: ones of $11.4 \pm 0.6 \mathrm{mmol} / \mathrm{L}$ for international-level competitors and ones of $14.5 \pm 1.2 \mathrm{mmol} / \mathrm{L}$ with national-level competitors. The values after technical and tactical tracings were $8.3 \pm 0.8 \mathrm{mmol} / \mathrm{L}$ for international-level Karate competitorsand $11.3 \pm 0.8$ $\mathrm{mmol} / \mathrm{L}$ for national-level Karate competitors, and after conditional training the values -5.3 $\pm 0.5 \mathrm{mmol} / \mathrm{L}$ and $7.9 \pm 0.6 \mathrm{mmol} / \mathrm{L}$, respectively.

The heart rate after the work rounds rose above $180 \mathrm{bpm}$ for all participants (except for participant S5, who showed $\mathrm{HR}=178 \mathrm{bpm}$ after the second round). In the break time the heart rate went down and varied from 120 to $140 \mathrm{bpm}$.

During an international competition, similar values were measured, namely $182 \pm 9 \mathrm{bpm}$ (Tabben et al., 2014). Therefore, it can be concluded that during international and national competitions the intensity of the strain is extremely high, which causes maximum cardiovascular responses and high lactate concentrations in the blood. In addition, these variables do not differ and remain high after the different matches during the competition. (Tabben et al., 2014). This suggests that coaches need to organize trainings in ways that they should simulate competition conditions as much as possible, so that the competitors will be ready for the high demands during important matches.

\section{CONCLUSIONS}

The values of the lactate concentration in the blood measured after each of the rounds of the circuit training indicated higher values that the values measured in competitions in the discipline of Kumite.

The values of the heart rate of the competitors that participated in the survey were close to the maximum and comparable to those measured at competitions.

At such immense strains, the concentration of the lactate was more indicative of the strain of the organism than was the heart rate.

The workloads in the circuit training model that we designed were of higher levels than were the workloads at competitions.

ACKNOWLEDGEMENTS: This study was supported by Grant CRAS-06/06-042017 from the National Sports Academy, Sofia, Bulgaria

\section{REFERENCES}

Beneke, R., Beyer, T., Jachner, C., Erasmus, J., and Hütler, M. (2004). Energetics of karate kumite. European Journal of Applied Physiology, Vol. 92, pp. 518-523.

Chaabène, H., Franchini, E., Miarka, B., Selmi, M.A., Mkaouer, B., and Chamari, K. (2014). Time-motion analysis and physiological responses to karate offcial combat sessions: is there a difference between winners and defeated karatekas? International Journal of Sports Physiology and Performance, Vol. 9, pp. 302-308.

Chaabène, H., Hachana, Y., Franchini, E., Mkaouer, B., and Chamari, K. (2012). Physical and physiological profle of elite karate athletes. Sports Medicine, Vol. 42, pp. 829-843.

Emberts, T., Porcari, J., Dobers-tein, S., Steffen, J. and Carl Foster (2013). Exercise Intensity and Energy Expenditure of a Tabata Workout, Journal of Sports Science and Medicine, Vol. 12, No.3, pp. 612-613.

Franchini, E., Ursula, J., Gonçalves, V., Lira, F., Agostinho, M., Henrique, B., and Branco, M. (2016). Short-term low-volume high-intensity intermitten training improves judo-specifc performance, Archives of Budo, 
Vol. 12, pp. 219-229.

Lehmann G. and Jedliczka G. (1998). Investigations on the determination and development of a sport-event-specific profile of the physical requirements in high-performance training for the sport of karate-kumite. Leistungssport, Vol. 28, pp. 56-61.

Schmidt, R.J., and Perry, J.G. (1976). Cardiac cost and heart rate response of karate kumite. Japanese Journal of Physical Education, Vol. 21, pp. 117-122.

Tabata, I., Nischimura, K., Kouzaki, M., Hirai, Y., Ogita, F., Miyachi, M., and Yamamoto, K. (1996). Effects of moderate-intensity endurance and high-intensity intermittent training on anaerobic capacity and VO2 max.
Medicine \& Science in Sports \& Exercise, Vol. 28, No.10, pp. 1327-1330.

Tabben, M., Coquart, J., Chaabène, H., Franchini, E., Chamari, K., and Tourny, C. (2014). Validity and reliability of new karate-specifc aerobic test for karatekas. International Journal of Sports Physiology and Performance, Vol. 9, pp. 953-958.

Tabben, M., Sioud, R., Haddad, M., Franchini, E., Chaouachi, A., Coquart, J., and Tourny-Chollet, C. (2013). Physiological and perceived exertion responses during international karate kumite competition. Asian Journal of Sports Medicine, Vol. 4, No. 4, pp. 263271.

\section{Corresponding author:}

Albena Alexandrova

Department "Physiology and Biochemistry" National Sports Academy "Vassil Levski" Studentski grad, 21, Acad. Stefan Mladenov str. Sofia 1700, Bulgaria E-mail: a_alexandrova_bas@yahoo.com 